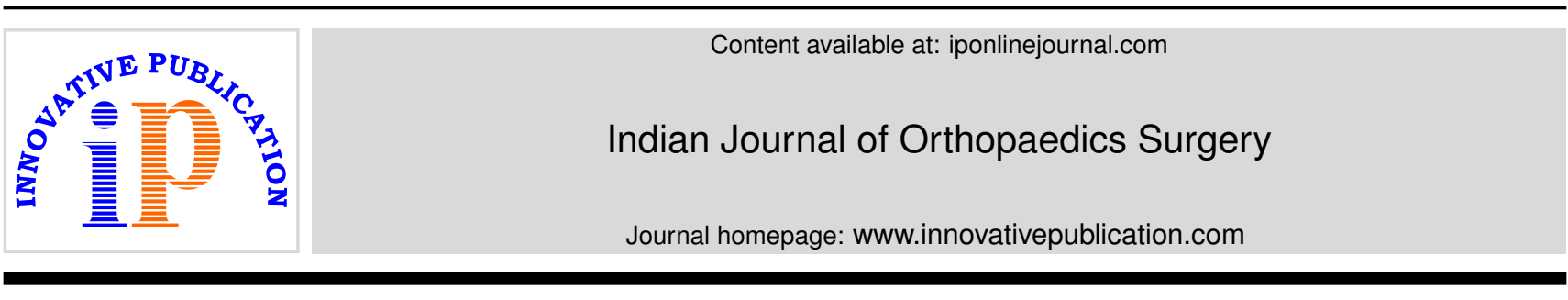

Original Research Article

\title{
A study of functional outcome following proximal humeral internal locking system plating for displaced proximal humeral fractures
}

\author{
Gnanesh V ${ }^{1}$, Chenna Keshava Rao ${ }^{1}$, Roshan S D ${ }^{1, *}$ \\ ${ }^{1}$ Dept. of Orthopaedics, KVG Medical College and Hospital, Sullia, Karnataka, India
}

\section{A R T I C L E I N F O}

\section{Article history:}

Received 08-11-2019

Accepted 03-01-2020

Available online 21-04-2020

\section{Keywords:}

Proximal humeral

PHILOS

Internal locking system plating

Fractures

\begin{abstract}
A B S T R A C T
Introduction: The proximal humerus fractures involve head, greater tuberosity, lesser tuberosity and proximal one-fourth of the shaft. It has been estimated that proximal humerus fractures account for nearly $4 \%$ of all the fractures and $26 \%$ of all the humerus factors.

Aim: To study the effectiveness of PHILOS in anatomical reduction and stability of fixation of displaced proximal humeral fractures.

Materials and Methods: It was a prospective study. All adult patients with fractures of proximal humerus who were admitted in Department of Orthopaedics of KVG Medical College and Hospital, Sullia, Karnataka were included for this study after informed written consent was obtained from them. The study period of the study was two years. The sample size was 25 for the scope of the study.

Results: Majority of the patients had four-part fracture according to the NEER's score. It was found that the overall performance of PHILOS was good on the basis of the follow-up done. The postoperative complications included perforation of screw. Co-morbidities like diabetes and RA were observed in the patients.

Conclusion: It was seen that the management of proximal humerus fractures with proximal humerus locking plates is associated with satisfactory (moderate) functional outcomes. Postoperative rehabilitation and encouragement for physical therapy also play a role in better functional outcomes.

(C) 2020 Published by Innovative Publication. This is an open access article under the CC BY-NC-ND license (https://creativecommons.org/licenses/by/4.0/)
\end{abstract}

\section{Introduction}

Those fractures occurring at the proximal to the neck of the humerus are known as the proximal humerus fractures (Siddalingamurthy et al., 2017). ${ }^{1}$ The proximal humerus fractures involve head, greater tuberosity, lesser tuberosity and proximal one-fourth of the shaft. It has been estimated that proximal humerus fractures account for nearly $4 \%$ of all the fractures and $26 \%$ of all the humerus factors (CourtBrown et al., 2006). ${ }^{2}$ It generally occurs in elderly patients aged 65 years or more (Thyagarajan et al., 2009). ${ }^{3}$ These fractures remain a challenge for the surgeon due to the place of dislocation and the age factor of the patients. There are two methods of treatment for such fractures conservative and operative. The selection of either of the two techniques depends on the degree of displacement and angulation of fracture fragments. Furthermore, there are many issues arising in the operative technique as age is the major factor influencing the decision of management. Some of the common issues faced during surgical treatment of proximal humerus fractures include osteoporotic bone, angular instability, implant impingement, bone loss, loss of reduction and backing out of screws. However, $20 \%$ of the proximal humerus fractures require operation, and Proximal Humerus Internal Locking System (PHILOS) has become the most widely used treatment technique (Hall and Rosser, 1963). ${ }^{4}$ Apart from the elderly patients, in the younger generation the problem of proximal humerus fracture is more severe.

\footnotetext{
* Corresponding author.

E-mail address: sdroshan@gmail.com (Roshan S D).
} 


\section{Aim and Objectives}

1. To study the effectiveness of PHILOS in anatomical reduction and stability of fixation of displaced proximal humeral fractures.

2. To analyse the functional outcome of management of displaced proximal humeral fractures by PHILOS by evaluating pain, activities of daily living, range of motion and muscle power.

\section{Materials and Methods}

This was a prospective study conducted at a K. V. G Medical hospital, from June 2017 to May 2019, on 25 patients with fractures of the proximal humerus. A total of 25 patients with the closed fractures of proximal humerus were managed with PHILOS plate during the study period.

A total of 25 patients without following any conventional sampling procedure were selected, fractures were classified as per the criteria of Neer classification (a part is defined as displaced more than $1 \mathrm{~cm}$ or with an angulation of more than $45^{\circ}$ ). Study inclusion criteria were closed displaced fracture 2part, 3part, 4part proximal humerus fractures, acute fractures ( $<1$ month old), age above 18 , and also fit for surgery were recruited for the study. Exclusion criteria were neurovascular injury, pseudoarthrosis, pathological fracture, refracture, open fracture, fracture more than one-monthold and associated post-traumatic brachial plexus injury or peripheral nerve palsy.

After routine OT profile investigations and pre anaesthetic check-up, patients were put under general anaesthesia with endotracheal intubation and were placed in a beach-chair position. All surgeries were performed using a deltopectoral approach. Post operatively all patients were immobilised in shoulder immobilisers, 5 doses of intravenous antibiotics were given to all the patients with first dose preoperatively and other 4 doses postoperatively. Immediate check $\mathrm{x}$-ray was taken to assess the alignment of bone and confirmation of optimal reduction. Shoulder pendulum, active assisted and passive exercises were started on 5 post operative day. Active shoulder exercises and rotational exercises were started once fracture union was evident on radiographs. Functional assessment was done using Constant Murley shoulder score. Follow-up done at 2 weeks, 4weeks, 6 weeks, 3 months and thereafter. Constant Murley shoulder score was graded as poor (055 points), moderate (56-70), good (71-85), excellent (86-100). Radiographs were taken at each follow-up to evaluate fracture union and any complication like fracture displacement, loss of reduction or varus, valgus angulation was also noted. Failure was defined as backing out of the screw, plate breakage /pull-out, malunion, nonunion or avascular necrosis of humeral head.

At final follow-up at 3 months patients were evaluated by Constant Murley score and radiographs were taken to assess for union or any complication mentioned above. Callus formation, presence of bridging osseous trabeculae and cortical continuity were considered as evidence of radiological union. Humeral head-shaft angle is the angle between humeral shaft axis and head. Head axis was taken as perpendicular to a line between the nearest lateral and medial points of the anatomic neck through the apex of the head. Head-shaft angle was further categorized as major varus (115 degrees), minor varus (115-124 degrees), normal (125-145 degrees), minor valgus (146-155 degrees), and major valgus (155 degrees) and compared between the immediate postoperative and last follow-up radiographs.

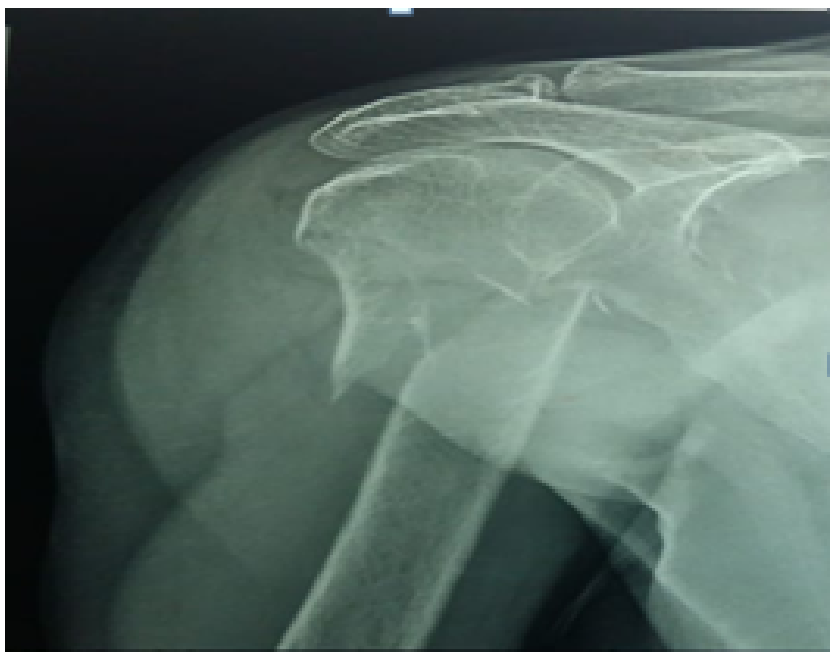

Fig. 1: Pre-operative x-ray
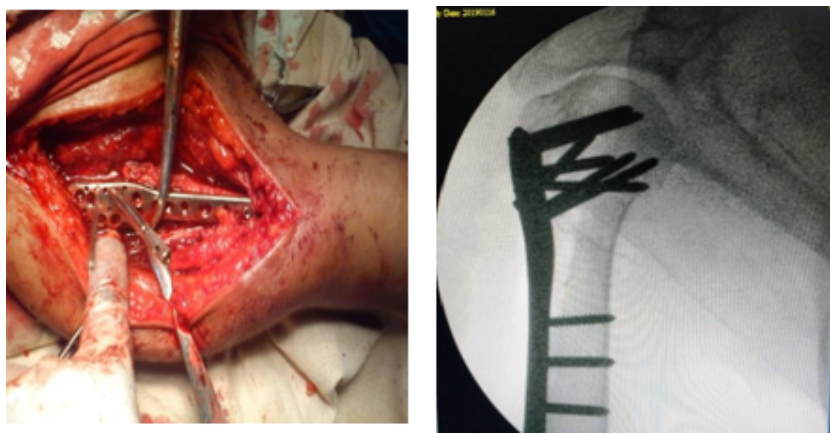

Fig. 2: Intra-operative

25 patients were taken for the scope of the study. Out of the 25,5 were females, and the remaining 20 were males. The average age of the patients was $43.12 \pm 13$.6 years. On the basis of NEER's.

It implies that the NEER's classification has proved to be helpful in the identification of the severity of the fracture. The results of the NEER's classification showed that the majority of the patients had a four-part fracture.

Out of total of 25 patients, 3 had diabetes, 2 had hypertension, 1 had heart disease, 1 had Rheumatoid 


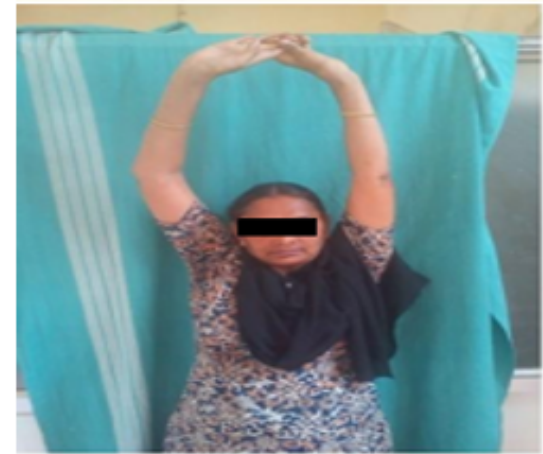

ABDUCTION

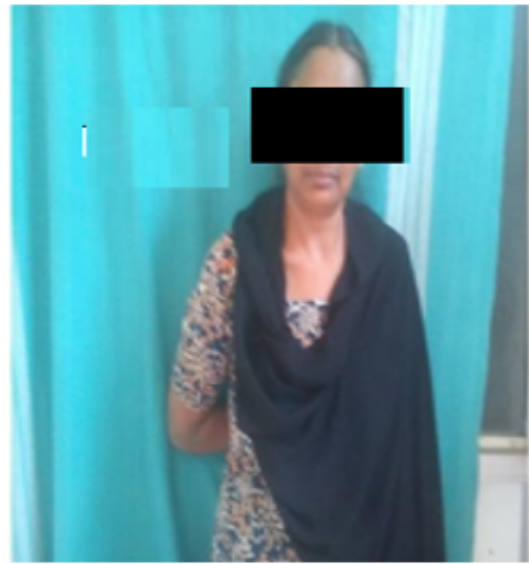

INTERNALROTATION

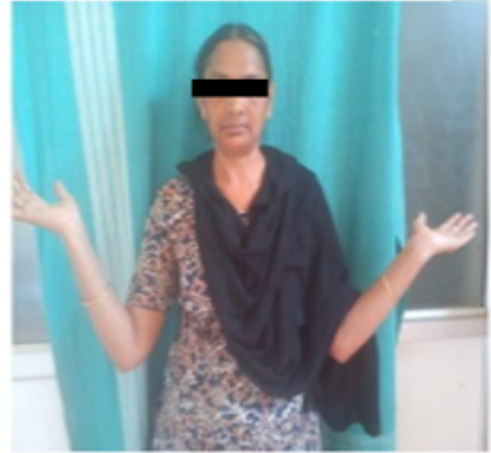

EXTERNAL ROTATION

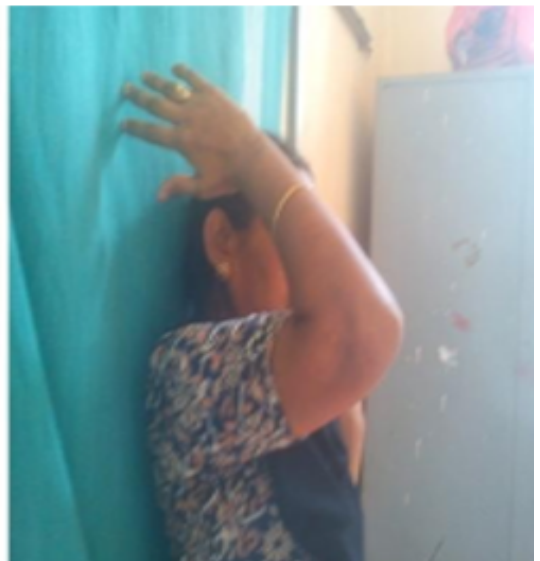

FLEXION

Fig. 4: Functional outcome

Table 1:

\begin{tabular}{|c|c|c|}
\hline NEER's classification & $\begin{array}{c}\text { Number of } \\
\text { patients }\end{array}$ & Percentage \\
\hline Two-part- surgical neck & 4 & $16 \%$ \\
\hline $\begin{array}{l}\text { Two-part- greater } \\
\text { tuberosity }\end{array}$ & 2 & $8 \%$ \\
\hline Three-part fracture & 9 & $36 \%$ \\
\hline Four-part fracture & 10 & $40 \%$ \\
\hline
\end{tabular}

Table 2:

\begin{tabular}{lcc} 
Co-morbidities & $\begin{array}{c}\text { Number of } \\
\text { patients }\end{array}$ & Percentage \\
Diabetes & 3 & $12 \%$ \\
Hypertension & 2 & $8 \%$ \\
Heart disease & 1 & $4 \%$ \\
Rheumatoid arthritis & 1 & $4 \%$ \\
None & 18 & $72 \%$ \\
\hline
\end{tabular}

arthritis, and none of the co-morbidities was present in 18 patients.
Table 3:

\begin{tabular}{lcc}
\hline Complications & $\begin{array}{c}\text { Number of } \\
\text { patients }\end{array}$ & Percentage \\
Perforation of screw & 2 & $8 \%$ \\
Chronic Osteomyelitis & 2 & $8 \%$ \\
Failure of Fixation & 1 & $4 \%$ \\
Osteonecrosis & 1 & $4 \%$ \\
Malunion/ non union & 1 & $4 \%$ \\
None & 18 & $72 \%$ \\
\hline
\end{tabular}

Out of 25 patients, 2 suffered Perforation of the screw, 2 suffered Chronic Osteomyelitis, 1 suffered Failure of Fixation, 1 suffered Osteonecrosis, 1 suffered Malunion/nonunion and the remaining 18 had no complications postsurgery.

Out of 25 patients, 5 reported the treatment to be excellent, 3 reported it to be good, 9 reported it to be moderate, 4 reported it to poorer, and the remaining 4 lost follow-up. 


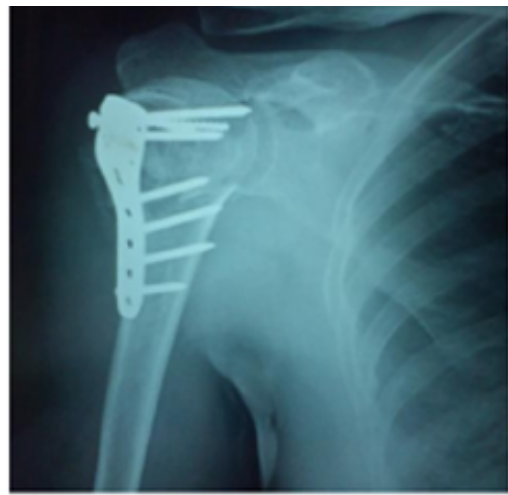

POST OPERATIVE

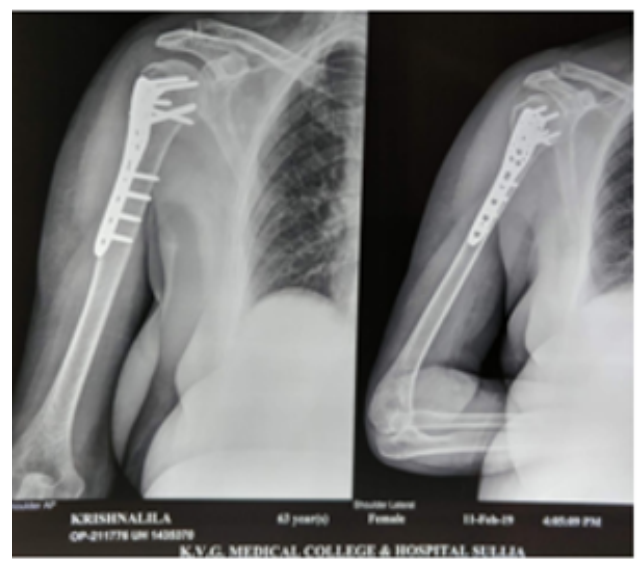

Fig. 3: Post operative

Table 4:

\begin{tabular}{lcc} 
Follow-up & $\begin{array}{c}\text { Number of } \\
\text { patients }\end{array}$ & Percentage \\
Excellent & 5 & $20 \%$ \\
Good & 3 & $12 \%$ \\
Moderate & 9 & $36 \%$ \\
Poorer & 4 & $16 \%$ \\
Lost follow-up & 4 & $16 \%$ \\
\hline
\end{tabular}

\section{Discussion}

Treating of proximal humeral fractures, especially for those patients suffering from osteoporosis is quite challenging for the surgeons. In the present study the majority of the patients had four-part fracture and three-part fracture. However, the studies of Kuchle et al. (2006) ${ }^{5}$ also showed similar results. In our study, it was found that the overall performance of PHILOS was good on the basis of the follow-up done. Furthermore, the study depicted that the functional results after rigid fixation of three- and four-part fractures using a locking plate were shown to be better than conservative treatment or semi-rigid fixation without anatomical reduction of the head fragment. Shoulder function continued to improve as the strength and function of the muscles increased. Similar results were obtained by Rizwan et al. (2008). ${ }^{6}$ The postoperative complications included perforation of screw which was absent in the study by Siddalingamurthy et al., (2017). ${ }^{1}$

\section{Conclusion}

It was seen that the management of proximal humerus fractures with proximal humerus locking plates is associated with satisfactory (moderate) functional outcomes. Postoperative rehabilitation and encouragement for physical therapy also play role in better functional outcomes. The surgeon must be well-versed with the anatomy as age factor is the major challenge in obtaining complex four-part fracturedislocations.

\section{Source of Funding}

None.

\section{Conflict of Interest}

None.

\section{References}

1. Siddalingamurthy G, Kiran HGR, Gowd BA, Darshan CK, Mruthyunjaya. Functional outcome of proximal humeral interlocking system plating for displaced proximal humeral fractures in adults. Int J Orthop Sci. 2017;3(2):32-7.

2. Court-Brown CM, Caesar B. Epidemiology of adult fractures: A review. Injury. 2006;37(8):691-7.

3. Thyagarajan DS. Functional outcome following proximal humeral interlocking system plating for displaced proximal humeral fractures. Int J Shoulder Surg. 2009;3(3):57-62.

4. Hall MC, Rosser M. The structure of the upper end of the humerus with reference to osteoporotic changes in senescence leading to fractures. Can Med Assoc J. 1963;88:290-4.

5. Küchle R, Hofmann A, Hessmann M, Rommens PM. The cloverleaf plate for osteosythesis of humeral head fractures. Definition of the current position. Unfallchirurg. 2006;109(12):1017-24.

6. Rizwan HS, Abid UM, Julian ON, Mohammad A. Outcome of proximal humerus fractures treated by PHILOS plate internal fixation Experience of a District General Hospital. Acta Orthop Belg. 2008;74:602-8.

\section{Author biography}

Gnanesh V Post Graduate

Chenna Keshava Rao HOD

Roshan S D Associate Professor

Cite this article: Gnanesh V, Rao CK, Roshan S D . A study of functional outcome following proximal humeral internal locking system plating for displaced proximal humeral fractures. Indian J Orthop Surg 2020;6(1):1-4. 